\title{
O ENEM e a leitura de textos filosóficos: análise de alguns parâmetros para a sala de aula ${ }^{11}$
}

Silvio Ricardo Gomes Carneiro ${ }^{12}$

\section{Resumo}

$\mathrm{O}$ artigo pretende apresentar uma análise crítica em continuidade com o trabalho desenvolvido por Ester de Macedo em Filosofia no ENEM. Traça tendências e problemas que a Filosofia porta consigo em avaliações como o ENEM. Além disso, procura analisar o impasse do conteúdo de Filosofia em um contexto neoliberal de avaliações de desempenho.

Palavras-chave: ENEM, avaliação de desempenho, currículo, filosofia, capital humano.

\section{The ENEM and reading philosophical texts: analysis of some parameters for the classroom}

\begin{abstract}
This paper intends to present a critical view in parallel with Ester de Macedo's Filosofia no ENEM. The paper observes trends and problems with the contents of Philosophy in the ENEM. Moreover, it tries to analise what problems the content of Philosophy have to face in a neoliberal contexto of performance tests.
\end{abstract}

Key words: ENEM, performance tests, curriculum, philosophy, human capital.

\section{Introdução}

Com mais de 15 anos integrando os processos de avaliação (1998 foi sua primeira edição), o ENEM - Exame Nacional do Ensino Médio - se configura como uma ferramenta importante para avaliação do ensino e proposição de didáticas que passam a interferir de maneira mais direta nos processos de aprendizagem. O estudo aqui apresentado é, na verdade, um balanço desse instrumento com enfoque no ensino de filosofia.

Em primeiro lugar, é preciso compreender a posição pela qual este exame se consolida como a segunda maior prova de acesso ao ensino superior do mundo, com 8.760.366 participantes voluntários inscritos este ano. ${ }^{13} \mathrm{Na}$ verdade o esforço não é pouco. Seus realizadores procuram escapar do modelo de acesso vestibular ao acumular nas notas do candidato o valor de seu desempenho durante o ensino médio, sendo uma avaliação oferecida

\footnotetext{
${ }^{11}$ Texto inicialmente apresentado no Encontro Nacional do GT Filosofar e Ensinar a Filosofar (ANPOF) em 2015. Apresentei uma nova versão para alunos da UFABC sob o impacto da edição de 2015 à convite do professor Alexander Freitas. Agradeço desde já, as observações dos professores e alunos que, de algum modo, procurei incorporar nessa versão.

${ }^{12}$ Professor de Filosofia do CCNH/UFABC. Contato: silvio.carneiro@ufabc.edu.br.

${ }^{13}$ Dados obtidos no site do MEC: http://painel.mec.gov.br (visitado em 25/02/2016).
} 
tanto para alunos egressos quanto concluintes do Ensino Médio. Surge, pois, como uma ferramenta que avalia não apenas o conhecimento adquirido pelo estudante no final de seu percurso, mas no seu decorrer.

O desafio dos idealizadores do ENEM também compreende a configuração de um formato adequado às normas e orientações que surgem desde a LDB de 1996. Desde lá, segue-se a orientação pedagógica que faz dos processos de ensino-aprendizagem não mais um exercício de memorização e, no mais feliz dos casos, de compreensão dos conteúdos transmitidos. Trata-se, de outro modo, do desenvolvimento de habilidades e competências entre os alunos capacitados com a produção crítica do conhecimento em sala de aula. ${ }^{14} \mathrm{De}$ acordo com o Relatório Pedagógico de 2008,

[o] modelo de avaliação do ENEM foi desenvolvido com ênfase na aferição das estruturas mentais com as quais constrói-se continuamente o conhecimento e não apenas na memória que, importantíssima na constituição dessas estruturas, sozinha não consegue fazer capaz de se compreender o mundo em que se vive, tal é a velocidade das mudanças sociais, econômicas, tecnológicas e do próprio acervo de novos conhecimentos, com os quais convive-se diariamente e que invadem todas as estruturas da escola. (...) O objetivo do ENEM é medir e qualificar as estruturas responsáveis por essas interações. (...) O ENEM focaliza, especificamente, as competências e habilidades básicas desenvolvidas, transformadas e fortalecidas com a mediação da escola. ${ }^{15}$

\footnotetext{
${ }^{14}$ Lembrando que o exame é o segundo maior do mundo, perdendo apenas para a China, onde os estudantes têm uma única chance para realizar o exame (v. o artigo "A segunda maior prova de acesso ao ensino superior do mundo" in http://portal.mec.gov.br/component/content/article?id=31151; visitado em 25/02/2015). Além disso, vale lembrar que os conceitos de habilidades e competências empregados desde então deverão ser revistos sob o prisma das Bases Nacionais Comuns Curriculares, submetida para consulta pública até 15 de março de $2016 .$. Nele, toda a gramática das habilidades e competências norteadoras nos Parâmetros Curriculares Nacionais (PCNs) e nas Orientações Curriculares para o Ensino Médio (OCEM) é substituída pelo ainda difuso conceito de "objetivos de aprendizagem". Talvez, uma maneira mais aproximada de tratar a questão do desenvolvimento ao campo do "direito à educação", oferecendo certa resistência à investida constante das habilidades e competências que fazem da educação uma das principais fontes de investimento do capital humano. Ou, de outra forma, uma maneira de aproximar o currículo escolar à forma de direitos de consumo do aluno, trazendo pela porta dos fundos a educação bancária sob a forma de mercadoria a ser consumida. Como um aviso na porta de entrada, lembremos Paulo Freire: “"Estudar não é um ato de consumir ideias, mas de cria-las e recriá-las" ("Considerações em torno do ato de estudar" in FREIRE, Ação cultural para a liberdade e outros escritos). Sobre o documento da Base Nacional Comum Currricular (BNCC), ver o site http://basenacionalcomum.mec.gov.br/\#/site/inicio (visitado em 25/02/2016). Sobre a teoria do capital humano e a questão das habilidades e competências ver, sobretudo, BECKER, Human Capital: a theoretical and empirical analysis with special reference to education. Sobre a transição das habilidades e competências para os objetivos de aprendizagem são poucas as análises, indicando a necessidade urgente de uma pesquisa nesse sentido. Para uma crítica dos objetivos de aprendizagem como direitos de aprendizagem, ver o artigo de CARA, "Países aprovam marco de ação para a educação global" in http://www.campanhaeducacao.org.br/?idn=1467 (visitado em 25/02/2016). Vale ainda perguntar em que medida o ENEM passará a ser influenciado por esse novo circuito curricular.

${ }^{15}$ BRASIL-INEP, Relatório Pedagógico do ENEM 2008, p. 47 - grifo nosso.
} 
Voltaremos mais adiante a este sentido de mensuração das habilidades e competências, que contem seus riscos. No momento, basta-nos compreender a virada em que o ENEM se insere e os desafios que extrai a partir daí para a construção de suas questões.

Decerto, tal modelo faz com que o estudante estabeleça com o conhecimento uma relação de outra ordem. Entretanto, o professor não se exime da tarefa de avaliar o desempenho de tal relacionamento. Podemos dizer, pois, que a maior dificuldade da confecção de provas como o ENEM reside neste ponto. Afinal, que tipos de questões devem ser propostas de modo a avaliar as habilidades e competências esperadas entre os estudantes?

Nesse sentido, o caso da filosofia é emblemático, pois o ENEM acompanha a trajetória da reinserção da disciplina no ensino médio, com duas matrizes principais de referência: a primeira de 1998 e a segunda de 2009, respondendo em grande medida à obrigatoriedade da disciplina a partir de 2008.

\section{A Filosofia no ENEM}

Sobre isso, recentemente foi publicado um estudo relevante que acompanha a trajetória da filosofia nas questões do exame: Filosofia no ENEM: um estudo analítico dos conteúdos relativos à filosofia ao longo das edições do ENEM de 1998 a 2011, de Ester de Macedo. Trata-se de um documento importante para nossas preocupações não apenas pelos resultados da investigação, mas também por nos orientar um método de investigação do tema (método que me valho nesta apresentação em grande medida), bem como apresenta o grau de impacto do ENEM em nossa sala de aula. Investigar estes três campos abertos por Macedo será a proposta de nossa apresentação.

Em primeiro, é necessário considerar que o ENEM se estrutura pelo regimento das Matrizes de Competências e Habilidades, documento organizado pela comissão governamental do ENEM. Até o momento, foram estabelecidos duas Matrizes (1998 e 2009). A primeira edição estabelecia que os itens do exame seriam distribuídos por 5 competências organizadas por 21 habilidades, totalizando 63 questões correspondentes às 21 habilidades reproduzidas em 3 níveis de dificuldade. A segunda edição das Matrizes, modificada sob o impacto da publicação das PCNs (1999 e 2001) e das OCEM (2008), traz consigo um leque maior de habilidades e competências, bem como novas estratégias de notas conforme as dificuldades das questões. A partir de 2009, aumentam para 180 questões referentes a 30 habilidades próprias às 6 competências indicadas nas Matrizes. Além disso, o ENEM passou a ser dividido entre as diversas ênfases, equilibrando a estrutura de disciplinas curriculares com a distribuição das habilidades e competências referidas nas Matrizes. No caso da Filosofia, suas questões passam a ser referidas na avaliação de Ciências Humanas e suas Tecnologias, juntamente com História, Geografia e Sociologia.

Diante deste quadro, Macedo chega às seguintes conclusões: 
entre 1999 e 2011 e que $40 \%$ desses itens se concentraram no ano de 2010 [é bom lembrar que a Filosofia não esteve presente nas edições do ENEM de 1998, 2002, 2004 a 2008]. O fato de cada uma das provas de 2009 e 2011 ter somente um item de filosofia entre os 45 de ciências humanas (uma percentagem menor do que durante a vigência da matriz anterior) indica que os mecanismos que conduzem à maior presença de filosofia nas provas do Enem ainda são precários. É necessário, portanto, um maior esforço no sentido de capacitar elaboradores e revisores de itens de filosofia para o Enem, a fim de aumentar tanto o número de itens na prova quanto sua qualidade. ${ }^{16}$

Decerto, a inquietação de Macedo pode ser relativamente revertida quando se aponta para os quadros subsequentes de 2012 a 2014, quando a filosofia esteve presente em novas 22 questões, recuperando assim o que estava sendo perdido na edição de 2011 (que, aliás continha uma única questão de texto jornalístico). Ou ainda, nas 8 questões de 2015, com a presença de autores mais contemporâneos (como Žižek) ou até pouco apresentados na formação acadêmica corrente da filosofia, como Paulo Freire e Simone de Beauvoir.

Sobre isso, é provável que esta retração e recuperação da Filosofia no ENEM seja fruto da própria preocupação da Comissão pedagógica do INEP. Sensível a esta percepção, o Relatório Pedagógico 2009-2010 afirma que o recente retorno da filosofia e da sociologia como disciplinas obrigatórias se tornou o "desafio maior da área de Ciências Humanas". ${ }^{17}$ Decerto, a matéria filosófica oferece certa resistência às questões de múltipla escolha, devido em grande medida ao teor reflexivo e crítico do exercício filosófico, muitas vezes oposto à necessidade objetiva de respostas em termos de "certo ou errado", "verdadeiro ou falso". Na verdade, das habilidades propriamente filosóficas (indicadas desde o PCN de 1999 e reproduzidas nos demais documentos posteriores e reproduzidas nos planos pedagógicos dos diversos níveis federativos - a ver na BNCC), as questões de filosofia do ENEM deixam de lado justamente competências centrais como a "elaboração escrita do que foi apropriado de modo reflexivo" e, por conta do próprio modelo do exame, o debate "tomando uma posição, defendendo-a argumentativamente e mudando de posição face a argumentos mais consistentes". ${ }^{18}$ Competências exercidas com constância nas salas de aula do ensino médio (muitas vezes de maneira confusa), mas ausentes nos termos do ENEM (talvez, na redação elemento que Macedo deixa de lado - um elemento que ainda carece de um olhar mais atento dos professores da filosofia). Sendo assim, o que resta da filosofia em exames como o ENEM?

\section{Método de investigação}

\footnotetext{
${ }^{16}$ MACEDO, Filosofia no ENEM, p. 101, grifo e colchetes nossos.

${ }^{17}$ BRASIL-INEP, Relatório Pedagógico 2009-2010, p. 61.

${ }^{18} \mathrm{MEC}, \mathrm{PCN}+$, p. 48.
} 
Macedo nos oferece um método interessante para avaliarmos a presença da filosofia no ENEM, associando as questões de cunho filosófico aos documentos de referência curricular, como as Matrizes de Competências e Habilidades da Comissão Governamental do ENEM (1998 e 2009), os PCNs (1999 e 2002) e as OCEM (2008). Tomemos aqui um exemplo:

\section{ENEM 2010 (1ª Aplicação) - Prova Rosa - Item 27}

O príncipe, portanto, não deve se incomodar com a reputação de ser cruel, se seu propósito é manter o povo unido e leal. De fato, com uns poucos exemplos duros poderá ser mais clemente do que outros que, por muita piedade, permitem os distúrbios que levem ao assassinato e ao roubo.

MAQUIAVEL, N., O Príncipe. São Paulo: Martin Claret, 2009.

No século XVI, Maquiavel escreveu “O Príncipe”, reflexão sobre a Monarquia e a função do governante. A manutenção da ordem social, segundo esse autor, baseava-se na:

A) inércia do julgamento dos crimes polêmicos.

B) bondade em relação ao comportamento dos mercenários.

C) compaixão quanto à condenação de transgressões religiosas.

D) neutralidade diante da condenação dos servos.

E) conveniência entre o poder tirânico e a moral do príncipe.

A cada questão, Macedo organiza um quadro que referencia o item às habilidades e competências indicadas nos documentos pedagógicos de referência do ENEM. No caso do exemplo, a autora opera da seguinte forma:

\begin{tabular}{|c|c|c|}
\hline PCN 1999 & $\begin{array}{l}1 \mathbf{a} \\
3\end{array}$ & $\begin{array}{l}\text { 1a) Ler textos filosóficos de modo significativo } \\
\text { 3) Contextualizar conhecimentos filosóficos, tanto no plano de sua origem } \\
\text { específica quanto em outros planos: o pessoal biográfico; o entorno } \\
\text { sociopolítico, histórico e cultural; o horizonte da sociedade científico- } \\
\text { tecnológica. }\end{array}$ \\
\hline $\mathrm{PCN}+2002$ & III.3 & Ética e política \\
\hline $\begin{array}{c}\text { OCEM } \\
2008\end{array}$ & 22 & Éticas do dever; fundamentação da moral; autonomia do sujeito \\
\hline C 2009 & $\mathbf{C 3}$ & $\begin{array}{l}\text { Compreender a produção e o papel histórico das instituições sociais, políticas } \\
\text { e econômicas, associando-as aos diferentes grupos, conflitos e movimentos } \\
\text { sociais. }\end{array}$ \\
\hline Н 2009 & H12 & Analisar o papel da justiça como instituição na organização das sociedades \\
\hline & + & Texto-base clássico \\
\hline & - & Distratores implausíveis \\
\hline
\end{tabular}

Nesse método de leitura das questões de Filosofia no ENEM, Macedo não procura fazer uma lista de conferência da presença ou ausência dos itens curriculares (mensurando a distribuição das habilidades e competências em filosofia nas diversas edições do ENEM), mas se preocupa com a questão formal da proposta ${ }^{19}$, elencando seus aspectos positivos e negativos (no caso, o uso de textos clássicos e os distratores implausíveis, respectivamente). 
No exemplo, os "distratores implausíveis" são um aspecto formal negativo da questão - aliás, um problema recorrente na apresentação da proposta de Filosofia no ENEM. Pois, quanto mais implausível o distrator, mais atrativa se torna a alternativa correta, deixando o aluno aquém do potencial do texto, que poderia ser melhor explorado na avaliação. $O$ distrator se torna implausível quando a alternativa apresenta conteúdos de forte contraste, ou mesmo contraditórios ao texto-base. No exemplo, enquanto o enunciado defende "uns poucos exemplos duros", as alternativas A, B, C e D falam de "inércia", "bondade", "compaixão" e "neutralidade", respectivamente. Ao aluno, basta o mínimo de atenção para resolver a questão. Este, aliás, é um problema recorrente no diagnóstico produzido por Macedo.

Quanto ao uso de textos clássicos como um aspecto positivo, é bom lembrar, não se trata de uma defesa dos originais por mero fetiche do conteúdo, mesmo porque, considera a autora do estudo,

a diversidade de fontes, assim como a articulação do clássico com o atual devem ser encorajadas. No entanto, o maior uso de textos filosóficos clássicos no ENEM serve a outro objetivo importante: fortalecer o espaço da filosofia, tanto no ENEM quanto no ensino médio. ${ }^{20}$

Encontrar um meio-termo capaz de adequar os textos clássicos da filosofia às exigências de um exame como o ENEM, sem cair no conteúdo a ser memorizado e nem na banalização do discurso filosófico é, pois, um problema a ser enfrentado nas propostas de questões como essa. As possibilidades são várias: explorando ora a articulação entre dois textos diversos (tanto apenas clássicos quanto mesclando com textos externos à filosofia; ora propondo modelos de análise diversos - entre enunciados com verdadeiro e falso, entre itens que se completam, articulando aspectos diversos de um mesmo campo de questões).

A partir desse quadro de variações, Macedo pode extrair algumas tendências do ENEM no que diz respeito às habilidades e competências do campo da filosofia promovidas pelo ENEM - e alguns problemas a partir daí. Elencamos aqui alguns deles:

a) $\underline{O}$ uso do texto-base: um número expressivo dos itens do ENEM (1998-2011) se valem de manuais e afins. Dos 22 itens apresentados no período da pesquisa, apenas 5 são originais (1999 e 2000, e outros 3 nas duas edições de 2010); Nas demais edições, ora são utilizados textos-clássicos adaptados, ora são utilizados manuais e antologias (deste último grupo, totalizam 5). Tais tendências estimulam os alunos a recorrerem aos manuais em detrimento dos textos clássicos da filosofia.

b) Contextualização da questão: um outro problema, dada a matriz do ENEM que procura escapar da memorização dos conteúdos transmitidos em nome do desenvolvimento das habilidades e competências, é a falta de contextualização da questão (no enunciado ou no texto-base). Ausência que, por vezes obriga o aluno a

${ }^{19} \mathrm{O}$ “+” (pontos positivos) e "_“" (pontos negativos), últimos itens do quadro de referência.

${ }^{20}$ MACEDO, Filosofia no ENEM..., p. 71. 
reconhecer pressupostos dos autores envolvidos, contrariando o princípio pedagógico da avaliação. Ou ainda pior, estimula-se a uma compreensão de filosofia externa ao exercício reflexivo, mas adequado a procedimentos que oferecem a ilusão de uma reflexão sem contexto e com resposta única ao longo da história da filosofia. Nesse sentido, Macedo problematiza inúmeras vezes os itens, cujos enunciados, além de descontextualizados, terminam com a expressão (comum em múltiplas escolhas): "Se $\mathrm{X}$, podemos afirmar que Y”, uma implicação nem sempre favorável ao raciocínio filosófico, reduzindo-o ao campo do certo ou errado.

c) Referencial das orientacões curriculares: Macedo atenta para a variação dos itens sob o impacto dos PCNs e das OCEM. ${ }^{21}$ Anteriormente a tais documentos, as competências e habilidades sugeridas tendiam à tarefa de articular conhecimentos filosóficos em textos de diferentes registros. Com o advento de tais documentos pelas novas Matrizes de Habilidades e Competências do ENEM, a tarefa maior se orienta pela contextualização de conhecimentos filosóficos. Ainda segundo a autora, a despeito da publicação das OCEM (pouco utilizado nos itens do ENEM) 22, é maior a influência do $\mathrm{PCN}+$ sobre os itens da filosofia, com maior presença do eixo temático II, sobre "a construção do sujeito moral" (concentrando em metade das questões), em correspondência com a tendência da presença da Filosofia no currículo em conformidade com o exercício da cidadania descrito na LDB. Acompanha também o eixo temático III, sobre "ética e política". Nesse sentido, acompanhamos a perspectiva de Macedo da forte influência dos PCN+ sobre a organização dos itens do ENEM.

\section{Filosofia no ENEM (2012-2015)}

A partir do diagnóstico de Macedo e o modo como a autora articula questões aos documentos de referência pedagógica do ENEM, é possível desdobrar alguns efeitos sobre o conteúdo filosófico do ENEM. Aventuro-me aqui a organizar novas tendências dos itens de Filosofia. $^{23}$

Quadro-Resumo
\begin{tabular}{|l|l|l|l|l|l|l|l|l|}
\hline Item & Prova & Texto-Base & Fonte & $\begin{array}{l}\text { PCN } \\
(\mathbf{1 9 9 9 )}\end{array}$ & $\begin{array}{l}\text { PCN+ } \\
(\mathbf{2 0 0 2})\end{array}$ & $\begin{array}{l}\text { OCEM } \\
(\mathbf{2 0 0 8})\end{array}$ & $\begin{array}{l}\mathrm{C}^{24} \\
(\mathbf{2 0 0 9})\end{array}$ & $\begin{array}{l}\mathbf{H}^{25} \\
\mathbf{( 2 0 0 9 )}\end{array}$ \\
\hline 1999.10 & Amarela & $\begin{array}{l}\text { Aquino, JP } \\
\text { II }\end{array}$ & Original & $\begin{array}{l}1 \mathrm{ab}, 2, \\
3\end{array}$ & III.1 & 14 & $\mathrm{C} 1$ & $\mathrm{H} 4$ \\
\hline 1999.31 & Amarela & $\begin{array}{l}\text { Copérnico, } \\
\text { Da Vinci }\end{array}$ & Original & $\begin{array}{l}1 \mathrm{ab}, 2, \\
3\end{array}$ & III.2 & $1 / 29$ & $\mathrm{C} 1$ & $\mathrm{H} 4$ \\
\hline
\end{tabular}

${ }^{21}$ Ver acima o quadro que relaciona a questão do exemplo 1 às habilidades e competências referentes aos documentos.

${ }^{22} \mathrm{O}$ que ainda se torna mais difícil pela reserva das OCEM quanto à transdisciplinaridade, em defesa da especificidade do conhecimento filosófico, contrariando as "ambiguidades" dos PCNs quanto ao lugar da disciplina no interior das ciências humanas.

${ }^{23}$ Sobre os códigos dos itens, ver ao final nosso anexo.

${ }^{24}$ Competências relativas ao documento Matrizes de Competências e Habilidades do ENEM (2009).

${ }^{25}$ Habilidades relativas ao documento Matrizes de Competências e Habilidades do ENEM (2009). 


\begin{tabular}{|c|c|c|c|c|c|c|c|c|}
\hline 2000.04 & Amarela & $\begin{array}{l}\text { Cícero, } \\
\text { Ulpiano }\end{array}$ & Original & $\begin{array}{l}\text { lab, 2, } \\
3\end{array}$ & II.1 & 22 & $\mathrm{C} 3$ & $\mathrm{H} 12$ \\
\hline 2000.52 & Amarela & Locke & Original & $1 \mathrm{a}, 2$ & II.1 & 20 & $\mathrm{C} 3$ & $\mathrm{H} 12$ \\
\hline 2000.53 & Amarela & Locke & Original & 1a, 3 & II. 1 & 20 & $\mathrm{C} 1$ & $\mathrm{H} 1$ \\
\hline 2001.18 & Amarela & Bacon & Original & 1a, 3 & III.2 & $1 / 29$ & $\mathrm{C} 1$ & $\mathrm{H1}$ \\
\hline 2001.30 & Amarela & $\begin{array}{l}\text { Hobbes, } \\
\text { Bobbio }\end{array}$ & Adaptado & 1a, 2 & II. 3 & 20 & $\mathrm{C} 3$ & $\mathrm{H} 12$ \\
\hline 2001.31 & Amarela & $\begin{array}{l}\text { Hobbes, } \\
\text { Bobbio }\end{array}$ & Adaptado & $1 \mathrm{ab}, 2$ & II. 3 & 20 & $\mathrm{C} 3$ & H14 \\
\hline 2001.57 & Amarela & Shakespeare & Original & $1 b, 2,3$ & III. 2 & $1 / 29$ & $\mathrm{C} 1$ & $\mathrm{H1}$ \\
\hline 2003.48 & Amarela & Montesquieu & Original & $1 \mathrm{a}, 3$ & II.1 & 22 & $\mathrm{C} 3$ & H14 \\
\hline 2009a.82 & Branca & Manual & Adaptado & $1 \mathrm{~b}, 2$ & II. 3 & 22 & $\mathrm{C} 3$ & $\mathrm{H} 12$ \\
\hline 2009b.58 & Azul & Aristóteles & Original & 1a & I.1 & 8 & $\mathrm{C} 1$ & $\mathrm{H} 01$ \\
\hline $2010 a .27$ & Rosa & Maquiavel & Original & 1a, 3 & II. 3 & 22 & $\mathrm{C} 3$ & $\mathrm{H} 12$ \\
\hline 2010a.28 & Rosa & Valéry & Original & $1 \mathrm{a}, 2$ & I.3 & 22 & $\mathrm{C} 3$ & $\mathrm{H} 14$ \\
\hline 2010a.34 & Rosa & Foucault & Original & $1 \mathrm{a}, 2$ & II. 3 & 30 & $\mathrm{C} 5$ & $\mathrm{H} 24$ \\
\hline 2010a.38 & Rosa & Manual & Adaptado & 1a & II. 3 & 22 & C5 & $\mathrm{H} 23$ \\
\hline 2010a.42 & Rosa & Quino & Original & $1 \mathrm{~b}, 2$ & II. 3 & 0 & C5 & $\mathrm{H} 24$ \\
\hline 2010a.44 & Rosa & Manual & Adaptado & $1 a, 3$ & II. 3 & 22 & $\mathrm{C} 5$ & $\mathrm{H} 23$ \\
\hline 2010b.27 & Azul & $\begin{array}{l}\text { Segurança e } \\
\text { Defesa } \\
\text { Nacional }\end{array}$ & Adaptado & $1 \mathrm{~b}, 2$ & II. 3 & 22 & $\mathrm{C} 5$ & $\mathrm{H} 23$ \\
\hline 2010b.34 & Azul & Habermas & Adaptado & $1 \mathrm{a}, 2$ & II. 3 & 28 & $\mathrm{C} 5$ & $\mathrm{H} 23$ \\
\hline 2010b.45 & Azul & culturabrasil & Adaptado & $1 \mathrm{~b}, 2$ & II.1 & 18 & $\mathrm{C} 1$ & $\mathrm{H} 03$ \\
\hline 2011.02 & Azul & Folha & Adaptado & $1 b, 2$ & II. 3 & 22 & $\mathrm{C} 5$ & $\mathrm{H} 23$ \\
\hline 2012.01 & Amarela & Habermas & Original & 1a, 2,3 & I. 2 & 28 & C5 & $\mathrm{H} 24$ \\
\hline 2012.08 & Amarela & Kant & Adaptado & 1a, 3 & II. 1 & 22 & C5 & $\mathrm{H} 23$ \\
\hline 2012.11 & Amarela & Montesquieu & Adaptado & 1a, 3 & $\mathrm{I} .2$ & 0 & $\mathrm{C} 5$ & $\mathrm{H} 23$ \\
\hline 2012.33 & Amarela & Zingano & Adaptado & 1a, 3 & III. 2 & 7 & $\mathrm{C} 1$ & $\mathrm{H} 5$ \\
\hline 2012.42 & Amarela & $\begin{array}{l}\text { Burnet, } \\
\text { Gilson } \\
\text { Boehner }\end{array}$ & Adaptados & $1 \mathrm{~b}, 3$ & III. 2 & 6 & $\mathrm{C} 1$ & $\mathrm{H} 5$ \\
\hline 2012.44 & Amarela & $\begin{array}{l}\text { Descartes e } \\
\text { Hume }\end{array}$ & $\begin{array}{l}\text { Original e } \\
\text { Adaptado }\end{array}$ & 1a, 3 & III. 2 & 17 & $\mathrm{C} 1$ & H5 \\
\hline 2012.45 & Amarela & Maquiavel & adaptado & $1 \mathrm{a}, 2,3$ & II. 3 & 18 & C5 & $\mathrm{H} 23$ \\
\hline 2013.01 & Amarela & Marx & Adaptado & $1 a, 2,3$ & II.1 & 28 & $\mathrm{C} 4$ & H16 \\
\hline 2013.21 & Amarela & Maquiavel & Original & $1 a, 3$ & II. 3 & 18 & $\mathrm{C} 5$ & $\mathrm{H} 23$ \\
\hline 2013.25 & Amarela & Montesquieu & Adaptado & 1a, 3 & I. 2 & 0 & $\mathrm{C} 3, \mathrm{C} 5$ & $\begin{array}{l}\mathrm{H} 12, \\
\mathrm{H} 23\end{array}$ \\
\hline 2013.30 & Amarela & Aristóteles & Original & 1a, 3 & III. 3 & 9 & $\mathrm{C} 5$ & $\mathrm{H} 23$ \\
\hline 2013.27 & Amarela & Cupani & Adaptado & $1 \mathrm{~b}, 3$ & III.2 & 17 & $\mathrm{C} 1$ & H5 \\
\hline 2013.39 & Amarela & $\begin{array}{l}\text { Descartes, } \\
\text { Franklin } \\
\text { Silva }\end{array}$ & Adaptados & $1 \mathrm{ab}, 3$ & III. 2 & 17 & $\mathrm{C} 1$ & H5 \\
\hline 2013.42 & Amarela & Kant & Adaptado & 1a, 3 & III. 2 & 23 & $\mathrm{C} 1$ & H5 \\
\hline 2014.06 & Amarela & Connor & Adaptado & $1 b, 2,3$ & III. 2 & 29 & $\mathrm{C} 4$ & H16 \\
\hline 2014.08 & Amarela & Habermas & Original & 1a, 3 & II.1 & 22,28 & $\mathrm{C} 3, \mathrm{C} 5$ & $\begin{array}{l}\mathrm{H} 12, \\
\mathrm{H} 24\end{array}$ \\
\hline 2014.13 & Amarela & Epicuro & Original & 1a, 3 & III. 3 & 9 & $\mathrm{C} 5$ & $\mathrm{H} 23$ \\
\hline 2014.14 & Amarela & Sanzio & $\begin{array}{l}\text { Original } \\
\text { (quadro) }\end{array}$ & 2 & $\begin{array}{l}\text { III.1, } \\
\text { III.2 }\end{array}$ & 7 & $\mathrm{C} 1$ & H5 \\
\hline 2014.16 & Amarela & $\begin{array}{l}\text { Franklin } \\
\text { Silva }\end{array}$ & Adaptado & $1 \mathrm{~b}, 3$ & $\begin{array}{l}\text { III.1, } \\
\text { III.2 }\end{array}$ & 11,17 & $\mathrm{C} 1$ & H5 \\
\hline
\end{tabular}




\begin{tabular}{|c|c|c|c|c|c|c|c|c|}
\hline 2014.21 & Amarela & $\begin{array}{l}\text { Tucídides, } \\
\text { Aristóteles }\end{array}$ & $\begin{array}{l}\text { Adaptado, } \\
\text { Original }\end{array}$ & $1 a, 2,3$ & I. $1, \mathrm{I} .2$ & 8 & $\mathrm{C} 1$ & $\mathrm{H} 4$ \\
\hline 2014.29 & Amarela & Galileu & Original & $1 \mathrm{a}, 2,3$ & III. 2 & $17(?)$ & $\mathrm{Cl}$ & H5 \\
\hline 2015.05 & Amarela & Beauvoir & Original & $1 \mathrm{a}, 2,3$ & I. 2, I. 3 & 22,26 & $\begin{array}{l}\mathrm{C} 1, \mathrm{C} 3, \\
\mathrm{C} 5\end{array}$ & $\begin{array}{l}\text { H3, } \\
\text { H13, } \\
\text { H22, } \\
\text { H24, } \\
\text { H25 }\end{array}$ \\
\hline 2015.11 & Amarela & $\begin{array}{l}\text { Nietzsche, } \\
\text { Pré- } \\
\text { socráticos }\end{array}$ & Original & 1a, 3 & I.1 & 6,25 & $\mathrm{C} 1$ & H5 \\
\hline 2015.12 & Amarela & Žižek & Original & $\begin{array}{l}1 \mathrm{a}, 1 \mathrm{~b}, \\
2,3\end{array}$ & I.3, II. 2 & 22 & $\begin{array}{l}\mathrm{C} 1, \mathrm{C} 3, \\
\mathrm{C} 5\end{array}$ & $\begin{array}{l}\text { H5, } \\
\text { H15, } \\
\text { H23, } \\
\text { H25 }\end{array}$ \\
\hline 2015.20 & Amarela & Hobbes & Original & $1 a, 3$ & II.1 & 20 & C3 & $\mathrm{H} 12$ \\
\hline 2015.29 & Amarela & Aquino & Original & 1a, 3 & II.1 & 18 & C3 & $\mathrm{H} 12$ \\
\hline 2015.34 & Amarela & Rachels & Manual & $1 b, 3$ & II.1 & 8 & C3 & $\mathrm{H} 12$ \\
\hline 2015.37 & Amarela & Hume & Original & $1 a, 3$ & III. 2 & 17 & $\mathrm{C} 1$ & H5 \\
\hline 2015.40 & Amarela & Paulo Freire & Original & $1 b, 3$ & II.1 & 22 & $\mathrm{C} 3$ & $\mathrm{H} 12$ \\
\hline
\end{tabular}

Ao contrário da tendência apontada por Macedo - e para alívio da presença da filosofia no exame - é possível dizer que nas edições do ENEM a partir de 2012, os itens de filosofia se fazem mais presentes, com maior incidência dos textos-base clássicos (ainda que adaptados), ou com o uso de trechos de comentadores da filosofia, como o texto de Franklin Leopoldo e Silva sobre Descartes. Desde este novo ciclo, o ENEM ofereceu 29 questões de filosofia (praticamente o mesmo número de itens das edições anteriores do ENEM). ${ }^{26}$ Dada a maior presença de textos clássicos da filosofia, exige-se nas edições mais recentes do exame que o estudante tanto opere leituras de textos filosóficos de modo significativo quanto contextualize conhecimentos filosóficos em sua origem ou com outros planos (biográficos, sociopolíticos, histórico e cultural). Com referência ao PCN+ (2002) é notável a maior exploração dos eixos temáticos próprios ao que é filosofia, com especial presença dos temas relativos à Filosofia da ciência (elemento raro nas edições anteriores a 2012) - movimento que recuou no ENEM de 2015 (com maior quantidade de questões sobre ética e democracia).

A despeito desse movimento, é possível dizer que a ressalva de Macedo ainda permanece, quando ela nota a maior influência dos PCNs na organização dos itens da filosofia do ENEM, a despeito de outros documentos mais recentes como as OCEM ou mesmo as Diretrizes curriculares nacionais da educação básica (2013). Contudo - e devido à maior recorrência à textos clássicos da Filosofia - é possível dizer que as novas edições do ENEM apelam mais à especificidade da Filosofia (o que aproximaria mais ao campo das OCEM), por vezes de maneira exagerada - uma vez que o enunciado da questão é apresentado sem contextualização (exigindo do estudante o reconhecimento dos pressupostos

\footnotetext{
${ }^{26}$ Desconsideramos aqui duas questões que estão na interface entre Filosofia e História. Uma questão que procura extrair considerações sobre as origens do totalitarismo, a partir de um texto de Hannah Arendt; outro, que extrai considerações das cidades-Estados gregas, a partir de um trecho de Vernant. Um problema que aguarda solução com o indicativo de Relatórios Pedagógicos mais recentes do INEP, ainda não publicados.
} 
da corrente filosófica em questão a despeito do enunciado). Alías, e também devido à maior especificidade filosófica, por vezes são selecionados materiais de autores e comentadores que se articulam a uma determinada corrente de pensamento, cujo conteúdo passa a ser o objeto de avaliação. ${ }^{27}$ Raros são os exercícios propostos de articulação de conhecimentos filosóficos e diferentes conteúdos e modos discursivos nas ciências naturais e humanas.

Por fim, e de acordo com última edição da Matriz de Habilidades e Competências do ENEM (2009), notamos na edição de 2015 um retorno das competências relativas à “compreensão da produção e o papel histórico das instituições associadas aos grupos sociais e seus conflitos" (C3). Movimento que contraria a tendência da edição anterior, quando praticamente estavam em equilíbrio competências relativas "compreensão dos elementos culturais que constituem as identidades" (C1) e aquelas outras relativas ao "uso de conhecimentos históricos para compreender e valorizar os fundamentos da cidadania e da democracia" (C5), em respeito à formação do indivíduo para a cidadania (prevista na LDB). Ressaltamos essa mudança sobretudo pelo impacto das últimas questões que, certamente, contrariaram a tendência de preparação dos estudantes nas apostilas de cursinhos e demais materiais didáticos, exigindo do candidato - não sei ao certo se uma reflexão - o confronto com perspectivas pouco comuns nas salas de aula, embora muito presentes na vida cotidiana.

Não à toa, a questão de Simone de Beauvoir causou tanta discussão. ${ }^{28}$ Nos termos da metodologia de Macedo, tratou-se de uma questão que exigiu do candidato os recursos à diversas competências e habilidades. Além das competências das Matrizes de 2009 acima mencionadas ( $\mathrm{C} 1, \mathrm{C} 2$ e $\mathrm{C} 3)$, o item contém a leitura de textos filosóficos de maneira significativa (PCN 1999 - 1a) e contextualizada (PCN 1999 - 3), a articulação do conteúdo filosófico à história e ciências políticas (PCN1999 - 2). Ou ainda, pensando o PCN+ (2002), o conceito de cidadania (I.2) e, novidade corajosa em tempos de discursos retrógrados na educação, ${ }^{29} \mathrm{o}$ debate do tópico do "fundamentalismo religioso e a política contemporânea. A

${ }^{27}$ Por exemplo, o uso de determinado enunciado de texto clássico de um autor do empirismo com as múltiplas escolas voltadas para determinada verdade dessa corrente filosófica. Naturalmente, é importante que o estudante reconheça determinada linha de pensamento, mas, sob a forma do exame e a perspectiva de avaliar as habilidades e competências do estudante e não mais o conteúdo transmitido, fica a questão: em que medida o ENEM responde às suas próprias matrizes pedagógicas?

28“Ninguém nasce mulher, torna-se mulher. Nenhum destino biológico, psíquico, econômico define a forma que a fêmea humana assume no seio da sociedade; é o conjunto da civilização que elabora esse produto intermediário entre o macho e o castrado que qualificam o feminino." BEAUVOIR, S. O segundo sexo. Rio de Janeiro: Nova Fronteira, 1980. Na década de 1960, a proposição de Simone de Beauvoir contribuiu para estruturar um movimento social que teve como marca o(a): A) ação do Poder Judiciário para criminalizar a violência sexual./ B) pressão do Poder Judiciário para impedir a dupla jornada de trabalho./ C) organização de protestos públicos para garantir a igualdade de gênero. /D) oposição de grupos religiosos para impedir os casamentos homoafetivos./ E) estabelecimento de políticas governamentais para promover ações afirmativas.

${ }^{29}$ Que circularam, aliás, na configuração dos planos de educação (nacional, estaduais, e municipais) em aprovação durante todo o ano de 2015 , com a forte presença de fundamentalismo religioso contrário a uma discussão necessária sobre gênero nas escolas e favorável ao retorno do ensino proselitista - ainda que denegado sob a forma da lei e do discurso da intolerância religiosa - de fundamentos religiosos. A questão de Beauvoir toca no ponto central destes discursos e, certamente, sua importante polêmica aponta quanto da intolerância religiosa está presente na ordem do dia. Diga-se de passagem, a lei que defende o ensino religioso obrigatório 
despeito de todos esses avanços, e mantendo nosso interesse de analisar o exame também em suas considerações pedagógicas, é necessário dizer que a forma da questão ainda peca pelo grau reduzido de dificuldade, mantendo distratores implausíveis, facilmente identificáveis por leitores que não estejam cegos por questões ideológicas. Pode ser querer exigir demais, mas talvez seja bom perguntar: em que medida não dispensamos uma oportunidade reflexiva rara sobre um argumento filosófico-existencial forte de Beauvoir ("Ninguém nasce mulher, tornase mulher") acerca da identidade dos sujeitos, associando o debate a alternativas de fácil idenficação, bastando o contraste simples entre o enunciado e as alternativas? "Criminalizar a violência", "jornada de trabalho", "grupos religiosos" e até "políticas governamentais" são termos distantes do enunciado da questão; termos que facilitam o raciocínio da múltipla escolha e, nesse sentido, reduz as possibilidades de reflexão possíveis em um interessante enunciado.

Portanto, a partir do ponto de vista de Macedo, é possível dizer que o cenário preocupante da presença rarefeita da filosofia no ENEM e com maior recurso a manuais e textos adaptados da filosofia, sofreu uma reversão positiva, na medida em que se exige do aluno maior contato com textos filosóficos originais; ou negativa, se o recurso à filosofia se reduzir a este escopo, em detrimento de seu potencial crítico e toda a vivência possível de sua presença em sala de aula.

\section{ENEM, as situações-problema, e a filosofia}

Muito embora todo o diagnóstico operado até aqui nos sirva como um bom material para compreendermos os discursos oficiais do Estado sobre o conteúdo de filosofia, é preciso considerar os limites desta operação. Uma ressalva cada vez mais importante quando o Ensino Médio anda sob risco de se tornar um ensino apostilado e de preparação para o ensino superior mediante o certificado do ENEM. É no mínimo preocupante, quando o ENEM conforme o próprio relatório pedagógico produzido pelo INEP - passa a ser exaltado não apenas por se tornar uma referência de auto-avaliação entre os alunos concluintes e egressos do ensino médio (com uma excelente amostragem para pesquisar as condições socioeconômicas desta população), mas também como objeto de interesse de empresas e do mundo do trabalho, que utilizam "os resultados do exame como forma auxiliar em seus processos de seleção profissional." 30

nas escolas e facultativo entre os alunos - uma aberração constitucional, se levarmos em conta não apenas a ambígua natureza facultativo-obrigatória dos sujeitos de direito, mas também pedagógicas, levando em conta o constrangimento que o aluno sofre ao exercer seu direito em não participar das aulas de religião. Diga-se de passagem, a formulação do art. 33 da LDB, que legitima constitucionalmente o ensino religioso obrigatório e facultativo foi a primeira alteração feita sobre a LDB, mostrando a força que a comunidade religiosa procura exercer na formação, conforme já indicava Florestan Fernandes no que dizia respeito à atuação da Igreja Católica na Assembleia Constituinte de 1987, atualmente estendido à outras bancadas religiosas no coração do Estado laico. V. FERNANDES, "Educação e constituição", in FERNANDES, A Constituição inacabada, pp. 120-123.

${ }^{30}$ INEP, Relatório pedagógico do ENEM 2008, p. 47. 
Em que medida, pois, tal instrumento de avaliação de desempenho do processo de formação integral do estudante do ensino médio (em suas diversas camadas: não apenas nas escolas, mas também entre adultos que desejam certificar seus estudos, ou ainda entre presidiários, conforme as edições mais recentes do exame) ainda pode ser um instrumento de diagnóstico do ensino nacional?

Aqui cabe uma reflexão sincera sobre a presença da filosofia nesses exames. É preciso ao menos lançar dúvidas de sua presença em exames como esse, cuja natureza tem em geral um modelo de aluno com conhecimentos adquiridos ao longo da escolarização que o tornem capaz de dominar a linguagem, compreender os fenômenos, enfrentar situações-problema, construir argumentações e elaborar propostas. ${ }^{31}$ Sobretudo, quando no campo mais específico desta avaliação, é central que o aluno se mostre capaz de "enfrentar situações-problema", molde presente na maior parte das questões do ENEM. Pois, a real dimensão de tal enfrentamento deve ser interpretada à luz da seguinte questão: podemos reduzir a experiência filosófica ao enfrentamento de situações-problema? Neste caso, qual o preço a se pagar? Ou ainda, o que resta da experiência de seu ensino na sala de aula? Sobre a posição oficial acerca destas questões, nada mais claro do que a própria descrição deste recurso pedagógico como o exemplo desenvolvido pelo Relatório pedagógico do ENEM (2008):

Tal como em um jogo de tabuleiro, enfrentar uma partida pressupõe o jogar dentro das regras - o jogar certo - sendo as regras aquilo que nos fornecem as coordenadas e os limites para nossas ações, a fim de percorrermos um certo caminho durante a realização da partida. (...) É a partir desse real dado - as regras -, que o jogador enfrentará o jogo, mobilizando seus recursos, selecionando certos procedimentos, organizando suas ações e interpretando informações para tomar decisões que considere as melhores naquele momento. ${ }^{32}$

Creio que aqui está um perigo já anunciado por Herbert Marcuse em $O$ homem unidimensional, quando explicitava a paralisia da crítica (e com ela, a experiência filosófica) diante do cenário do pensamento unidimensional. Ali, o filósofo comentava do sistema de paralisia da crítica através de um sistema de oposições integradas.

Decerto, comenta o autor, seria possível a divergência no campo aparentemente democrático da esfera pública. Contudo, tal regimento de oposições não escapava das "regras do jogo": mudam-se as peças, desde que se mantenha intacto o tabuleiro. Nesse sentido, é curioso que o termo "pensamento crítico" esteja cada vez menos presente nos discursos de ensino-aprendizagem da filosofia. Mudança de vocabulário fundamental para pensarmos na gramática nova do ensino. Mudança que exige pensarmos a presença da filosofia em um tabuleiro tão cheio de peças e armadilhas como a educação.

\footnotetext{
${ }^{31}$ INEP, Relatório pedagógico do ENEM 2008, p. 55.

${ }^{32}$ INEP, Relatório pedagógico 2008, pp. 58-59. Sobre isso, vale ressaltar que a centralidade das situaçõesproblema como central também para o relatório pedagógico mais recente (2009-2010).
} 
Podemos reduzir o ensino de filosofia a isso? Ou ainda, como gerar um discurso sobre o ensino de filosofia com suas reais proporções e com alcance nacional? Preocupação a meu ver legítima em vistas de um sistema de ensino cada vez mais orientado para a acumulação do capital humano. Processo de produção de conhecimento que não escapa dos desígnios dos organizadores do ENEM, presente nas palavras de tranquilidade pronunciadas recentemente por José Francisco Soares, presidente do INEP, em recente entrevista:

To Enem premia o esforço (...) da pessoa e nos compete garantir que seja essa a linha do ENEM, a linha mestra que... depois de termos feito tudo o que fizemos nós vamos dizer quem fez mais esforço do que outra pessoa. ${ }^{33}$

Ora, seria a filosofia ainda filosofia quando a medida de tudo não é mais o humano, mas o capital que este humano carrega consigo?

\section{ANEXO: CÓDIGO DAS HABILIDADES E COMPETÊNCIAS DE ACORDO COM OS DOCUMENTOS OFICIAIS ${ }^{34}$}

\begin{tabular}{|c|c|}
\hline PCN 1999 & $\begin{array}{l}\text { 1a: Ler textos filosóficos de modo significativo } \\
\text { 1b: Ler, de modo filosófico, textos de diferentes estruturas e registros. } \\
\text { 2: Articular conhecimentos filosóficos e diferentes conteúdos e modos discursivos } \\
\text { nas Ciências Naturais e Humanas, nas Artes e em outras produções culturais. } \\
\text { 3: Contextualizar conhecimentos filosóficos, tanto no plano de sua origem } \\
\text { específica quanto em outros planos: o pessoal biográfico; o entorno sociopolítico, } \\
\text { histórico e cultural; o horizonte da sociedade científico-tecnológica. }\end{array}$ \\
\hline $\mathrm{PCN}+2002$ & $\begin{array}{l}\text { I. Relações de poder e democracia } \\
\text { 1: Mito e Filosofia: o nascimento da Filosofia na Grécia } \\
\text { - A ágora e a assembleia } \\
\text { - Democracia direta } \\
\text { 2: A democracia direta: } \\
\text { - Antecedentes (Montesquieu/Rousseau) } \\
\text { - Liberalismo e socialismo } \\
\text { - O conceito de cidadania } \\
\text { 3: Fundamentalismos religiosos e a política contemporânea } \\
\text { - Totalitarismos de direita e de esquerda } \\
\text { - Fundamentos religiosos e a política contemporânea } \\
\text { II. A construção do sujeito moral } \\
\text { 1: Autonomia e liberdade } \\
\text { - Descentração do indivíduo e o reconhecimento do outro } \\
\text { - As várias dimensões da liberdade } \\
\text { - Liberdade e determinismo } \\
\text { 2: As formas da alienação moral } \\
\text { - Individualismo contemporâneo e a recusa do outro } \\
\text { - As condutas massificadas na sociedade contemporânea } \\
\text { 3. Ética e política } \\
\text { - Maquiavel } \\
\text { - Cidadania: os limites entre o público e o privado }\end{array}$ \\
\hline
\end{tabular}




\begin{tabular}{|c|c|}
\hline & $\begin{array}{l}\text { III. O que é Filosofia } \\
\text { 1. Filosofia, mito e senso comum } \\
\text { - Mito e filosofia } \\
\text { - Mitos contemporâneos } \\
\text { - Do senso comum ao pensamento filosófico } \\
\text { 2. Filosofia, ciência e tecnocracia } \\
\text { - Características do método científico } \\
\text { - O mito do cientificismo } \\
\text { - A tecnologia a serviço dos objetivos humanos e os riscos da tecnocracia } \\
\text { - Bioética } \\
\text { 3. Filosofia e estética } \\
\text { - Os diversos tipos de valor } \\
\text { - A arte como forma de conhecer o mundo } \\
\text { - Estética e desenvolvimento da sensibilidade e imaginação }\end{array}$ \\
\hline OCEM 2008 & $\begin{array}{l}\text { 1: Filosofia e conhecimento; Filosofia da ciência; definição de Filosofia } \\
\text { 2: Validade e verdade; Proposição e argumento } \\
\text { 3: Falácias não-formais; Reconhecimento de argumentos; Conteúdo e forma } \\
\text { 4: Quadro de oposições; Inferências imediatas em contexto categórico; Conteúdo } \\
\text { existencial e proposições categóricas } \\
\text { 5: Tabelas de verdade; Cálculo proposicional } \\
\text { 6: Filosofia pré-socrática: uno e múltiplo; movimento e realidade } \\
\text { 7: Teoria das ideias em Platão; Conhecimento e opinião; Aparência e realidade } \\
\text { 8: Política antiga; a República de Platão; a Política de Aristóteles } \\
\text { 9: a ética antiga; Platão, Aristóteles e filósofos helenistas; } \\
\text { 10: conceitos centrais da metafísica aristotélica; a teoria da ciência aristotélica; } \\
\text { 11: verdade, justificação e ceticismo; } \\
\text { 12: o problema dos universais; os transcendentais; } \\
\text { 13: tempo e eternidade; conhecimento humano e conhecimento divino; } \\
\text { 14: teoria do conhecimento e do juízo em Tomás de Aquino; } \\
\text { 15: a teoria das virtudes no período medieval; } \\
\text { 16: provas da existência de Deus; argumentos ontológico, cosmológico, teleológico; } \\
\text { 17: Teoria do conhecimento nos modernos; verdade e evidência; ideias; } \\
\text { causalidade; indução; método } \\
\text { 18: Vontade divina e liberdade humana } \\
\text { 19: teorias do sujeito na filosofia moderna; } \\
\text { 20: O contratualismo } \\
\text { 21: razão e entendimento; razão e sensibilidade; intuição e conceito; } \\
\text { 22: Éticas do dever; fundamentações da moral; autonomia do sujeito } \\
\text { 23: idealismo alemão; filosofias da história; } \\
\text { 24: razão e vontade; o belo e o sublime na Filosofia alemã; } \\
\text { 25: Crítica à metafísica na contemporaneidade: Nietzsche; Wittgenstein; Heidegger } \\
\text { 26: Fenomenologia; existencialismo } \\
\text { 27: Filosofia analítica; Frege, Russell e Wittgenstein; o Círculo de Viena; } \\
\text { 28: marxismo e Escola de Frankfurt; } \\
\text { 29: epistemologias contemporâneas; Filosofia da ciência; o problema } \\
\text { da demarcação } \\
\text { entre ciência e metafísica; } \\
\text { 30: Filosofia francesa contemporânea; Foucault; Deleuze. }\end{array}$ \\
\hline $\begin{array}{l}\text { MATRIZES } \\
\quad 2009 \\
\text { Competências } \\
\text { \& } \\
\text { Habilidades }\end{array}$ & $\begin{array}{l}\text { C1: Compreender os elementos culturais que constituem as identidades } \\
\text { H1: Interpretar historicamente e/ou geograficamente fontes } \\
\text { documentais acerca de aspectos } \\
\text { da cultura. } \\
\text { H3: Associar as manifestações culturais do presente aos seus processos } \\
\text { históricos. }\end{array}$ \\
\hline
\end{tabular}




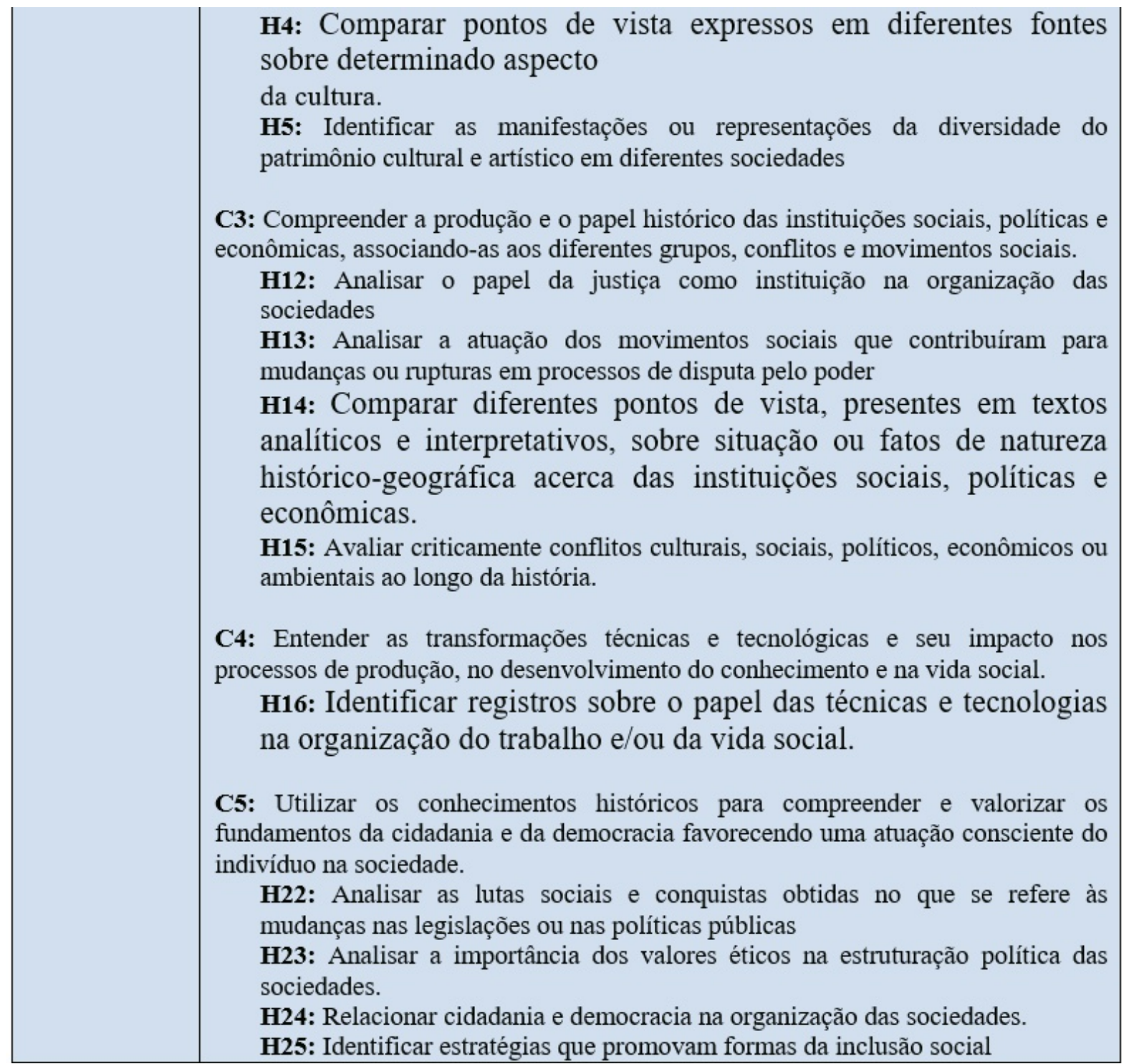

Submetido em agosto de 2015. Aprovado para publicação em setembro de 2015.

\section{REFERÊNCIAS}

BECKER, Gary S.. Human capital: a theoretical and empirical analysis with special reference to education, $3^{\text {a }}$ ed., Chicago, London: Chicago University Press, 1993.

BRASIL. Instituto Nacional de Estudos e Pesquisas Educacionais (Inep). Relatório pedagógico do Enem 2003. Brasília, DF: Inep, 2007.

BRASIL. Instituto Nacional de Estudos e Pesquisas Educacionais (Inep). Relatório pedagógico do Enem 2008. Brasília, DF: Inep, 2009. 
BRASIL. Instituto Nacional de Estudos e Pesquisas Educacionais (Inep). Matrizes de referência para o ENEM 2009, Brasília, DF: Inep, 2009. Disponível em: http://portal.mec.gov.br/index.php?option=com_docman\&view=download\&alias=841matriz-1\&category_slug=documentos-pdf\&Itemid=30192 (visitado em 25/02/2016)

BRASIL - MEC. A segunda maior prova de acesso ao ensino superior do mundo in http://portal.mec.gov.br/component/content/article?id=31151; artigo de 05 de outubro de 2015. (visitado em 25/02/2016).

BRASIL - MEC/SEB, Base nacional curricular comum (documento para consulta pública até 15/03/2015) in http://basenacionalcomum.mec.gov.br/\#/site/inicio (visitado em $25 / 05 / 2016$ )

BRASIL-MEC/SEB. Orientações curriculares para o ensino médio - ciências humanas e suas tecnologias (vol. 3). Brasília: Ministério da Educação/Secretaria de Educação Básica,

2006.

http://portal.mec.gov.br/seb/arquivos/pdf/book_volume_03_internet.pdf. Visitado em 25/02/2016.

BRASIL-MEC/SEMT. Parâmetros curriculares nacionais para o ensino médio ciências humanas e suas tecnologias, Brasília: Ministério da Educação/Secretaria de Educação Média e Tecnológica, 1999. Disponível em: http://portal.mec.gov.br/seb/arquivos/pdf/cienciah.pdf (vistado em 25/02/2016).

BRASIL-MEC/SEMT. PCN+ - Orientações educacionais complementares aos parâmetros curriculares nacionais - ciências humanas e suas tecnologias. Brasília: Ministério da Educação/Secretaria de Educação Média e Tecnológica, 2002. Disponível em: http://portal.mec.gov.br/seb/arquivos/pdf/CienciasHumanas.pdf (visitado em 25/02/2016).

BRASIL-MEC/SEB, DICEI. Diretrizes curriculares nacionais gerais da educação básica. Ministério da Educação. Secretaria de Educação Básica. Diretoria de Currículos e Educação Integral. Brasília: MEC, SEB, DICEI, 2013.

CARA, Daniel. Países aprovam marco de ação para a educação global in http://www.campanhaeducacao.org.br/?idn=1467. Artigo de 12/11/2015. (visitado em 25/02/2016). 
FERNANDES, A Constituição inacabada: vias históricas e significado político, São Paulo: Estação liberdade, 1989.

FREIRE, Paulo. Ação cultural para a liberdade e outros escritos, $5^{\mathrm{a}}$. ed, Rio de Janeiro: Paz e Terra, 1981.

MACEDO, Ester P. N de. Filosofia no ENEM: um estudo analítico dos conteúdos relativos à Filosofia ao longo das edições do ENEM entre 1998 e 2011, Brasília, DF: Inep, 2015.

MARCUSE, Herbert. O homem unidimensional: estudos da ideologia da sociedade industrial avançada. Tradução de: Robespierre de Oliveira et al., São Paulo: Edipro, 2015. 